\title{
Psicodinâmica do Trabalho no Brasil: Revisão Sistemática da Literatura
}

\author{
Carmem Regina Giongo ${ }^{{ }^{*}}$ \\ Programa de Pós-Graduação em Psicologia Social e Institucional da Universidade Federal \\ do Rio Grande do Sul, Porto Alegre, RS, Brasil \\ Janine Kieling Monteiro \\ Centro de Ciências da Saúde da Universidade do Vale do Rio dos Sinos, \\ Leopoldo, RS, Brasil \\ Gênesis Marimar Rodrigues Sobrosa \\ Programa de Pós-Graduação em Psicologia Clínica da Universidade do Vale do Rio \\ dos Sinos, São Leopoldo, RS, Brasil
}

\begin{abstract}
Resumo
A psicodinâmica do trabalho tem assumido um importante papel nos estudos brasileiros sobre saúde/doença mental do trabalhador. Desta forma, este estudo possui o objetivo de realizar uma revisão sistemática dos artigos, teses e dissertações nacionais que utilizaram a teoria e/ou o método da psicodinâmica do trabalho nos últimos anos (janeiro de 2007 a dezembro de 2013). Para a busca dos materiais utilizou-se o descritor psicodinâmica do trabalho na Biblioteca Virtual em Saúde Psicologia (BVS-Psi), na Base de Teses e Dissertações da Coordenação de Aperfeiçoamento de Pessoal de Nível Superior (CAPES) e na Biblioteca Digital Brasileira de Teses e Dissertações. Os resultados apontaram que os estudos, em sua grande maioria, estão pautados em métodos qualitativos, investigando vivências de prazer e de sofrimento dos trabalhadores e que a categoria profissional mais estudada é a dos trabalhadores da área da saúde. A análise dos principais resultados dos estudos indicou que as pesquisas brasileiras que utilizam a psicodinâmica do trabalho possuem uma forte característica descritiva, apontando para a necessidade de mais estudos com foco na intervenção e na discussão de ações de promoção da saúde do trabalhador.
\end{abstract}

Palavras-chave: Psicodinâmica do trabalho, saúde mental, trabalho, revisão sistemática.

\section{Psychodynamics of Work in Brazil: Systematic Review of Literature}

\begin{abstract}
Psychodynamics of work has assumed an important role in Brazilian's studies concerning health/mental illness of workers. Therefore, this study has the objective of doing a systematic review of articles, theses and national dissertations which used the theory and/or the psychodynamics of work in the last few years (2007 to 2013). To collect materials the descriptor work psychodynamics was used in the Virtual Library in Health Psychology (BVS-Psi), in the database of Tests and Dissertations of Coordination for the Improvement of Higher Education Personnel (CAPES) and the Digital Brazilian Library
\end{abstract}

Endereço para correspondência: Rua Conselheiro D’Avila, 354, Apto. 202, Bairro Jardim Floresta, Porto Alegre, RS, Brasil 91040-450. Fone: (51) 9271-1901. E-mail: ca.aiesec@gmail.com, janinekm@unisinos.br e genesispsi@yahoo.com.br 
of Theses and Dissertations. The result showed that the majority of studies are based in qualitative methods, investigating experiences of pleasure and pain of workers, and the most studied professional category is the workers from the health area. The analysis of the main results revealed that the Brazilian researches which employ the Work Psychodynamics have a strong descriptive characteristic, pointing to the necessity of more studies with focus on intervention and discussion of actions promoting worker's health.

Keywords: Work psychodynamics, mental health, work, systematic review.

\section{Psicodinámica del Trabajo en Brasil: Revisión Sistemática de la Literatura}

\section{Resumen}

La psicodinámica del trabajo ha cobrado un rol importante en los estudios brasileños sobre salud/enfermedad mental del trabajador. De esta manera, este estudio tiene el objetivo de realizar una revisión sistemática de artículos, tesis y disertaciones nacionales que utilizaron la teoría y/o el método de la psicodinámica del trabajo en los últimos años (enero de 2007 a diciembre de 2013). Para la búsqueda de los materiales, se utilizó el descriptor psicodinámica del trabajo en la Biblioteca Virtual en Salud Psicológica (BVS-Psi), en la base Biblioteca Brasileña de Tesis y Disertaciones. Los resultados apuntan que los estudios, en su mayoría, están guiados por métodos cualitativos, investigando vivencias de placer y sufrimiento de los trabajadores; y la categoría profesional más estudiada es la de los trabajadores del área de la salud. El análisis de los principales resultados muestra que las investigaciones brasileñas que utilizan la psicodinámica del trabajo poseen un fuerte rasgo descriptivo, evidenciando la necesidad de más estudios con énfasis en la intervención y en la discusión de acciones de promoción de la salud del trabajador.

Palabras clave: Psicodinámica del trabajo, salud mental, revisión sistemática.

A abordagem da psicodinâmica do trabalho foi apresentada por Dejours, através da publicação na França de Travail: Usure Mentale. Essai de Psychopathologie du Travail, em 1980, traduzido no Brasil com o nome de A Loucura do Trabalho: Estudo de Psicopatologia do Trabalho, em 1987 (Merlo, 2002). A obra trouxe um novo olhar para a compreensão das relações entre trabalho e saúde psíquica do trabalhador e passou a ser entendida como um importante referencial para a área da clínica e da saúde mental no trabalho, capaz de subsidiar estudos e intervenções teórica e metodologicamente (Merlo \& Mendes, 2009).

O percurso da psicodinâmica do trabalho foi caracterizado por três fases diferentes, cada uma, representada por publicações específicas. O primeiro momento teve início na década de 80 e foi marcado pela publicação da obra Travail, Usure
Mentale-Essai de Psychopathologie du Travail, que denominava a teoria como psicopatologia do trabalho e buscava compreender o sofrimento e o modo como os trabalhadores lidavam com ele. Com a publicação do addendun à décima edição de Travail, Usure Mentale - Essai de Psychopathologie du Travail e do Le Facteur Humain na década de 90 , o enfoque da teoria passou a ser o estudo das vivências de prazer e de sofrimento no trabalho, pensando nas nuances do trabalho prescrito e do trabalho real, além de considerar a construção da identidade do trabalhador. No final da década de 90 ocorreu a consolidação da psicodinâmica do trabalho como abordagem científica, representada pelas publicações de Souffrance em France e L'évaluation du Travail à L'épreuve du Réel: Critique dês Fondementes de L'évaluation. Nestas obras a teoria passou a estudar as novas configurações das organizações 
do trabalho, as estratégias defensivas, as patologias sociais e o sentido das vivências de trabalho (Mendes, 2007a).

A psicodinâmica do trabalho privilegia a clínica como modo de construção do conhecimento, de interpretação e de análise do trabalho, colocando-se como instrumento capaz de compreender tanto os processos de saúde quanto as patologias do trabalho (Mendes, 2007b). Nesta perspectiva, saúde no trabalho não significa ausência de sofrimento, mas o potencial que cada trabalhador possui de utilização dos recursos internos e externos para transformação do sofrimento na busca pelo prazer e realização. Esta dinâmica é marcada pela utilização de estratégias defensivas capazes de mobilizar os trabalhadores de maneira individual ou coletiva, estabelecendo uma relação mais gratificante com o trabalho e também buscando o reconhecimento, fator essencial no processo de construção da identidade do trabalhador (Mendes, 2004). Outro aspecto muito importante na procura do prazer e defesa diante do sofrimento no trabalho é a mobilização subjetiva, definida como o processo pelo qual o trabalhador se engaja no trabalho e consegue fazer uso da subjetividade, inteligência prática e do coletivo de trabalho para transformar os fatores da organização do trabalho causadores de sofrimento (Dejours, 2005).

Nesta abordagem, a organização do trabalho ocupa um papel fundamental no entendimento dos processos de saúde/doença do trabalhador, sendo sua rigidez inversamente proporcional à saúde mental. $\mathrm{O}$ conceito de organização do trabalho pode ser divido em duas esferas, sendo uma delas caracterizada pela divisão do trabalho e a outra pela divisão dos homens (Dejours, 1992). Na divisão do trabalho estão os aspectos relacionados à organização das tarefas, aos processos prescritos, ao modo de produção, entre outros. Na divisão dos homens estão as responsabilidades relacionadas ao trabalho, as relações de poder, as hierarquias, o comando, o grau de autonomia nas atividades, e as possibilidades de cooperação e comunicação, entre outros. É através da análise psicodinâmica das vivências do trabalhador relacionadas à organização do trabalho que se fará o entendimento dos processos atrelados à saúde/doença no trabalho. Neste contexto, a organização do trabalho representa uma realidade social enquanto mobiliza e também é mobilizada pelo trabalhador, que por sua vez, coloca sua subjetividade e constitui a intersubjetividade no trabalho (Mendes \& Facas, 2011).

Esta análise propõe o entendimento da dinâmica existente no contexto de trabalho, que pode ser definida pela "atuação de forças, visíveis e invisíveis, objetivas e subjetivas, psíquicas, sociais, políticas e econômicas que podem ou não, deteriorar esse contexto, transformando-o em lugar de saúde e/ou de patologias e de adoecimento" (Mendes, 2007a, p. 29). Tendo em vista esta perspectiva, uma das principais contribuições da psicodinâmica do trabalho é a de expor os efeitos que a organização do trabalho pode gerar na saúde mental do trabalhador, além de oferecer instrumentos para que estes efeitos sejam identificados ainda no campo prépatológico, possibilitando atuações preventivas e capazes de compreender e intervir nos processos de saúde/doença mental no trabalho (Merlo \& Mendes, 2009).

Esta abordagem pode subsidiar estudos de maneira teórica e/ou metodológica. Enquanto teoria pode ser utilizada para análise e compreensão de aspectos relacionados à saúde mental e trabalho, através de discussões teóricas ou da aplicação de conceitos vindos da psicodinâmica do trabalho para delinear ou interpretar dados de pesquisa empírica. Enquanto método segue os pressupostos apresentados por Dejours (2004), que propõe as seguintes etapas de pesquisa: pré-enquete; enquete; análise da demanda; análise do material da enquete; observação clínica; interpretação; validação e refutação; e validação ampliada. Este método dejouriano tem como aspecto fundamental a escuta clínica do trabalho, realizada através de um espaço compartilhado por um grupo de trabalhadores, onde o pesquisador favorece a circulação da fala e a escuta das vivências intersubjetivas sobre o trabalho, visando à ressignificação do sofrimento no trabalho. Neste sentido, caracteriza-se como uma pesquisa-ação, pois através deste espaço público e da elaboração e perlaboração do que é dito, poderá acontecer uma ação que venha modificar o 
real do trabalho (Dejours, Abdoucheli, \& Jayet, 1994; Merlo \& Mendes, 2009).

Um levantamento realizado por Merlo e Mendes (2009) de publicações que utilizaram a teoria e/ou o método da psicodinâmica do trabalho entre os anos de 1996 e 2009 mostrou que os estudos existentes faziam muito mais uso da teoria do que do método de pesquisa proposto, apontando para uma menor apropriação por parte dos pesquisadores brasileiros acerca das possibilidades metodológicas e práticas da abordagem. Como o foco do levantamento esteve pautado na discussão sobre uso do método e/ou da teoria da psicodinâmica do trabalho, os autores apontaram para a necessidade de levantamentos que buscassem outros parâmetros de comparações entre os estudos publicados, além de classificações mais conclusivas sobre as perspectivas do uso da abordagem no Brasil. Tendo em vista este apontamento e também a importância da psicodinâmica do trabalho para os estudos no campo da clínica do trabalho e da saúde do trabalhador no Brasil, este estudo possui o objetivo de realizar uma revisão sistemática dos artigos, teses e dissertações nacionais que utilizaram a teoria e / ou o método da psicodinâmica do trabalho nos últimos anos (janeiro de 2007 a agosto de 2012). Neste sentido, o presente trabalho visa contribuir para a ampliação de estudos no campo da psicodinâmica do trabalho, identificando eventuais lacunas existentes na área.

\section{Método}

Primeiramente foi realizada uma análise das bases de dados nacionais capazes de oferecerem resultados consistentes e atualizados no campo da Psicologia, sendo escolhida para a pesquisa de artigos a Biblioteca Virtual em Saúde Psicologia (BVS-Psi) e para a pesquisa de teses e dissertações a Base de Teses e Dissertações da Coordenação de Aperfeiçoamento de Pessoal de Nível Superior (CAPES) e a Biblioteca Digital Brasileira de Teses e Dissertações (BDTD). O critério de escolha destas fontes ocorreu por serem consideradas as mais abrangentes entre as disponíveis até o momento e por agregarem fontes consistentes de dados científicos.
A BVS-Psi faz a indexação de teses, monografias, textos didáticos, Index Psi Livros, Lilacs (Literatura Latino-Americana e do Caribe em Ciências da Saúde), PePSIC (Periódicos Eletrônicos de Psicologia) e SciELO (Scientific Electronic Library Online), e permite realizar serviços de comutação e consulta a catálogos de periódicos nacionais. A Base de Teses e Dissertações da CAPES disponibiliza consulta online de teses e dissertações produzidas no Brasil, que são fornecidas pelas instituições de pós-graduação existentes. A BDTD também realiza a integração e publicação das teses e dissertações existentes nas instituições de ensino e de pesquisa no Brasil.

A consulta às bases de dados, empreendida para este artigo de revisão, se deu no período de outubro de 2012 a abril de 2013. A busca dos artigos na BVS-Psi foi realizada através do descritor psicodinâmica do trabalho. $\mathrm{Na}$ sequência foram acessadas separadamente as fontes SciELO, PePSIC e Portal Revistas da Universidade de São Paulo (USP) e realizada uma primeira triagem considerando o período de publicação. Para o levantamento de teses e dissertações foi realizada, primeiramente, uma busca na BDTD. Posteriormente, foi selecionada a opção de busca avançada, onde foi preenchido o país de busca, neste caso Brasil, o assunto a ser pesquisado, psicodinâmica do trabalho e o intervalo desejado, janeiro de 2007 a dezembro de 2013. Na sequência foi realizada a pesquisa na Base de Teses e Dissertações da CAPES considerando apenas publicações nacionais e o assunto: psicodinâmica do trabalho. Nesta base, a busca por teses e dissertações foi realizada separadamente, conforme opção do portal. Em seguida também os anos foram consultados individualmente.

Diante dos resultados obtidos nas buscas foi realizada a leitura dos títulos, dos resumos e, em alguns casos, dos textos completos. Foram eliminados os materiais que não disponibilizavam texto completo, que estavam repetidos entre as bases ou que não possuíam relação com o assunto pesquisado. No total das buscas foram identificados 197 trabalhos. Destes, um material foi excluído por não disponibilizar texto com- 
pleto, 22 foram descartados por estarem repetidos entre as bases, 31 foram eliminados por conteúdo, 71 foram excluídos por estarem fora do período estipulado para a análise, e 73 foram aproveitados.

Um exemplo dos materiais excluídos por assunto é o artigo intitulado: Maturidade ou Imaturidade na Escolha da Carreira: Uma Abordagem Psicodinâmica (Bordão-Alves \& Melo-Silva, 2008) que não trata da psicodinâmica do trabalho, mas sim, da psicodinâmica como abordagem psicanalítica para o atendimento clínico individual. De modo geral os materiais excluídos tratavam de assuntos como: qualidade de vida no trabalho; gestão de pessoas; legislação trabalhista; psicoterapia psicodinâmica; intervenções na clínica psicanalítica; psicoterapia breve; psicologia da mediunidade; depressão; maternidade e depressão; escolha de carreira; sentido do trabalho; trabalho e intersubjetividade; riscos psicossociais; aprendizagem organizacional; biossegurança; humanização das práticas de saúde e alcoolismo.

Com o intuito de refinar a análise dos 73 materiais aproveitados foram criadas categorias organizadas da seguinte maneira: (a) tipo de publicação, na qual foi identificado se o material era um artigo teórico ou empírico, tese ou dissertação; (b) área de publicação (de acordo com a classificação do Conselho Nacional de Desenvolvimento Científico e Tecnológico [CNPQ]), sendo considerada em primeiro lugar a instituição de origem do estudo e quando a instituição não estava especificada, a formação do primeiro autor; (c) ano de publicação dos estudos; (d) categorias profissionais investigadas, de acordo com cada categoria profissional; (e) temáticas dos objetivos principais, analisadas e organizadas por categorias teóricas de acordo com a frequência de utilização; (f) delineamento dos estudos, de acordo com as descrições realizadas pelos autores; (g) instrumentos de coleta de dados, obtidos através do detalhamento metodológico dos estudos; e (h) principais resultados, identificados através de análise de conteúdo dos estudos empíricos. A categoria principais resultados dos estudos foi analisada qualitativa- mente e organizada em tópicos de acordo com os resultados declarados pelos materiais. Como exemplo, no tópico estratégias defensivas foram incluídas e agrupadas todas as estratégias defensivas citadas pelos estudos. As demais categorias foram analisadas quantitativamente, de acordo com a frequência que apareceram nos estudos aproveitados.

\section{Análise e Discussão dos Resultados}

Os artigos, teses e dissertações utilizadas para a análise sistemática deste estudo estão relacionados abaixo.

\section{Tipo de Publicação}

Quanto ao tipo de publicação foram identificadas 4 teses, 19 dissertações e 50 artigos publicados. Deste total, 10 materiais eram teóricos e 63 eram empíricos. A predominância de estudos empíricos contribui na medida em que se utiliza da psicodinâmica e levanta dados sobre a real situação dos trabalhadores brasileiros, mas, por outro lado, pode representar uma carência de revisões teóricas sobre a abordagem. Estas revisões poderiam contribuir para o amadurecimento da psicodinâmica do trabalho enquanto teoria e método no Brasil, além de promover reflexões sobre suas particularidades, possibilidades e limitações.

As duas revistas que mais publicaram os artigos utilizados foram Psicologia, Ciência e Profissão, que representa estudos diversificados na área de Psicologia e a Revista Brasileira de Saúde Ocupacional, voltada para as questões atreladas à relação saúde e trabalho, conforme ilustrado na Tabela 1. As revistas que publicaram dois artigos ou menos foram classificadas na coluna outros. Entre as revistas classificadas em outros estão: Interface: Comunicação, Saúde, Educação; Cadernos de Saúde Pública; Saúde e Sociedade; Psicologia: Teoria e Pesquisa; Gestão e Produção; Revista Latino-Americana de Enfermagem; Revista de Saúde Pública; entre outras. 
Tabela 1

Frequência das Publicações por Revista

\begin{tabular}{cc}
\hline Nome da Revista & Número de Publicações \\
\hline Psicologia, Ciência e Profissão & 5 \\
Revista Brasileira de Saúde Ocupacional & 4 \\
Psicologia e Sociedade & 3 \\
Revista da Escola de Enfermagem da USP & 3 \\
Cadernos de Psicologia Social do Trabalho & 3 \\
Revista Psicologia: Organizações e Trabalho & 3 \\
Outros & 29 \\
\hline
\end{tabular}

\section{Área de Publicação}

A área que mais realiza publicações utilizando a psicodinâmica do trabalho é a Psicologia (46 estudos), depois a Engenharia de Produção (9 estudos), a Enfermagem (8 estudos), a Administração (5 estudos), a Saúde Coletiva e a Fisioterapia/Terapia Ocupacional (com 3 estudos e 2 estudos respectivamente) e a Nutrição (1 estudo). Estes dados corroboram os resultados do levantamento realizado por Merlo e Mendes (2009) que apontou para o uso da teoria e/ou método da psicodinâmica do trabalho por diferentes áreas de atuação, possivelmente, preenchendo lacunas nas discussões destas áreas. A Psicologia permanece em primeiro lugar na utilização da psicodinâmica do trabalho em estudos envolvendo o trabalhador e o universo do trabalho.

\section{Ano de Publicação dos Estudos}

A distribuição dos estudos por período indica que o ano de 2009 obteve maior registro de publicações e que, nos anos seguintes, houve uma redução na produção de estudos relacionados à psicodinâmica do trabalho, conforme aponta Tabela 2. Este fato pode ser explicado talvez por um aumento de publicação de artigos internacionais, reduzindo o número de publicações nacionais e/ou pelo processo relativamente demorado de publicações de artigos nas revistas brasileiras. De qualquer modo, este dado merece ser mais explorado em outras investigações.
Tabela 2

Distribuição de Publicações por Ano

\begin{tabular}{cc}
\hline Ano & Número de Artigos \\
\hline 2013 & 9 \\
2012 & 6 \\
2011 & 8 \\
2010 & 11 \\
2009 & 19 \\
2008 & 13 \\
2007 & 8 \\
\hline
\end{tabular}

\section{Categorias Profissionais Investigadas}

Foi identificada grande variedade nas categorias profissionais investigadas, dentre as quais se destacaram os trabalhadores da área da saúde (19 estudos), os trabalhadores sociais (8 estudos), os artistas (5 estudos), os policiais e agentes de trânsito (6 estudos) e os trabalhadores de plataformas de petróleo (3 estudos). Os grupos de trabalhadores que contemplaram no máximo 2 e no mínimo 1 estudo foram classificados como outros e corresponderam a 22 estudos. Entre estes, estão presentes: os bancários, os consultores, os trabalhadores de call center, os pastores, os pesquisadores, os trabalhadores de plantações de cana-de-açúcar, os designers de moda, os trabalhadores deficientes físicos e auditivos, entre outros. 
Apesar do grupo profissionais da área da saúde ser o mais estudado, foi possível observar uma grande variedade de trabalhadores investigados, o que vem ao encontro da singularidade do trabalho humano, pois os construtos teóricos da abordagem privilegiam a subjetividade e as particularidades das vivências do trabalhador ou de uma categoria profissional. Observou-se que as investigações acerca dos trabalhadores rurais são escassas se comparadas aos trabalhadores urbanos, o que pode ser explicado pela dificuldade de acesso a estes profissionais, aspecto já evidenciado pela literatura (Schlindwein, 2010; Silva, 2007).

Tabela 3

Temáticas dos Objetivos Principais

\section{Temáticas dos Objetivos Principais}

A análise dos objetivos principais dos estudos mostrou que as categorias teóricas mais investigadas são as vivências de prazer e de sofrimento dos trabalhadores, além dos fatores da organização do trabalho, conforme dados da Tabela 3. Os objetivos dos estudos parecem corresponder aos eixos centrais da abordagem da psicodinâmica do trabalho, mas, por outro lado, muitos deixam de inserir outras temáticas emergentes, tais como: trabalho imaterial, estratégias de enfrentamento, mobilização subjetiva, cooperação, inteligência prática, reconhecimento, entre outras. A investigação destas temáticas poderia tornar os estudos mais complexos e abrangentes, além de auxiliar no avanço da construção de uma teoria mais sólida da psicodinâmica do trabalho no Brasil.

\begin{tabular}{cc}
\hline Temáticas & Número de Artigos \\
\hline Vivências de Prazer e Sofrimento & 21 \\
Organização do Trabalho e Prazer e Sofrimento & 19 \\
Reflexões Teóricas sobre PdT & 10 \\
Segurança no Trabalho & 7 \\
Vivências de Trabalho & 6 \\
Estratégias Defensivas & 4 \\
Intervenções & 2 \\
Subjetividade / Sentidos do Trabalho & 2 \\
Terceirização & 1 \\
Reabilitação e Reinserção no Trabalho & 1 \\
\hline
\end{tabular}

Nota . PdT = Psicodinâmica do trabalho.

\section{Delineamento dos Estudos}

Quanto ao delineamento das investigações, a abordagem qualitativa se mostrou presente em 55 estudos, enquanto as revisões teóricas contemplaram 9 estudos, os estudos de caso 5 estudos, os métodos mistos 4 estudos, a triangulação de métodos 1 estudo e o delineamento quantitativo também 1 estudo. Apoia o uso do delineamento qualitativo a perspectiva de Dejours (2004) de que o prazer, o sofrimento, o afeto, a experiência e a dimensão subjetiva não são objetivos e só podem ser acessados através da palavra. Na abordagem, é através da fala que o sujeito nomeia e compreende o que sente, sendo esta reflexão responsável pela produção de novos sentidos e por uma consciência ampliada das experiências vividas.

\section{Instrumentos de Coleta de Dados}

Quanto aos instrumentos de coleta de dados, prevaleceu, em 35 estudos, o uso de instrumentos conjuntos, tais como: entrevistas, sessões de 
grupo, grupos focais, observação e análise documental. Na sequência, as entrevistas (individuais e/ou coletivas) foram utilizadas em 25 estudos. O uso de escala ou inventário apareceu em 4 estudos e os registros clínicos de atendimentos em 1 estudo.

Estes resultados mostram-se coerentes à proposta da abordagem da psicodinâmica do trabalho, apesar de refletirem adaptações do método originalmente proposto por Dejours (2004). Neste sentido, a utilização de variados instrumentos de coleta de dados também pode preencher as lacunas existentes na aplicação do método da psicodinâmica, que nem sempre é possível de ser realizado por envolver diversos encontros grupais com os trabalhadores. Outra condição para o estudo aplicar o método é a existência de uma demanda por parte dos profissionais ou da instituição, mas em muitas situações, a demanda vem do próprio pesquisador ou do grupo de pesquisa. Portanto, os estudos utilizarem diversos instrumentos de coleta de dados, possivel- mente, contribui para o aumento da qualidade das investigações e aponta para uma adaptação da metodologia da psicodinâmica ao contexto e condições dos trabalhadores brasileiros. Apesar de flexíveis com relação à aplicação da metodologia da abordagem, muitos estudos deixam de apresentar e discutir as flexibilizações realizadas, impedindo o avanço da implementação ou adaptação da teoria e do método da abordagem.

\section{Principais Resultados dos Estudos}

A análise dos principais resultados apresentados nos estudos foi divida em seis eixos temáticos:

1. Fatores de prazer;

2. Fatores de sofrimento;

3. Estratégias defensivas;

4. Mobilização subjetiva;

5. Adoecimento mental e

6. Intervenção. A descrição dos eixos temáticos extraídos dos resultados dos estudos pode ser observada na Tabela 4 .

\section{Tabela 4}

\section{Caracterização dos Principais Resultados}

\begin{tabular}{|c|c|}
\hline Categoria & Sub-categoria \\
\hline \multirow{3}{*}{ Fatores de Prazer } & Sentido do trabalho \\
\hline & Organização do trabalho \\
\hline & Reconhecimento \\
\hline \multirow{3}{*}{ Fatores de Sofrimento } & Sentido do trabalho \\
\hline & Organização do trabalho \\
\hline & Reconhecimento \\
\hline \multicolumn{2}{|l|}{ Estratégias Defensivas } \\
\hline \multicolumn{2}{|l|}{ Mobilização Subjetiva } \\
\hline \multicolumn{2}{|l|}{ Adoecimento Mental } \\
\hline \multirow{2}{*}{ Intervenção } & Pesquisa-intervenção \\
\hline & Alternativas de intervenções \\
\hline
\end{tabular}

No eixo fatores de prazer foram descritos todos os aspectos da organização do trabalho e também da subjetividade do trabalhador que proporcionam prazer no trabalho, sendo constituído por três subcategorias:
1. Sentido do trabalho, onde se destacaram os processos de identificação dos trabalhadores com suas atividades laborais, o orgulho que sentem da profissão, a possibilidade de ajudar as pessoas e o fato de o trabalho 
influenciar positivamente nos hábitos de vida;

2. Organização do trabalho, onde estão descritas as relações sócio-profissionais positivas e a possibilidade de cooperação, a autonomia para o desenvolvimento das atividades, a infraestrutura de trabalho adequada e aconchegante, os níveis hierárquicos informais que permitem melhor divisão das tarefas, o clima de trabalho amistoso, a remuneração satisfatória e a possibilidade de desenvolvimento pessoal; e

3. Reconhecimento, gerado pela conquista de metas e resultados.

A descrição do eixo fatores de prazer corrobora o que foi destacado por Bruch e Monteiro (2011) de que as relações entre colegas, nas quais exista cooperação, apoio e confiança, podem contribuir para a promoção de vivências de prazer e para a saúde mental no trabalho. Além disso, o sentido atribuído ao trabalho aparece como um importante fator de prazer, pois é através dele que o trabalhador reconhece a importância de suas atividades laborais para si e para os outros. O fator reconhecimento foi pouco mencionado nos estudos e poderia receber maior destaque nas investigações, visto que assume um papel central na transformação do sofrimento em prazer e na construção da identidade do trabalhador.

O eixo fatores de sofrimento foi descrito pelos aspectos da organização do trabalho e também da subjetividade do trabalhador que geram vivências de sofrimento no trabalho. Este eixo também foi organizado por três subcategorias, sendo que organização do trabalho se divide em outros quatro tópicos:

1. Sentido do trabalho: caracterizado pela perda da identidade profissional, pelos conflitos entre os valores da empresa e os valores pessoais dos trabalhadores e pela ausência de perspectivas de crescimento profissional;

2. Organização do trabalho: (a) organização do trabalho que gera sobrecarga por: intensa exigência de doação ao trabalho e busca pela perfeição nas atividades, dificuldade na realização das tarefas, necessidade de agradar o cliente interno e externo em to- dos os momentos, controles de qualidade, excessiva burocracia nos processos, intensas mudanças na organização do trabalho, pressões com relação às metas e resultados, volume e ritmo exacerbado de trabalho; (b) organização do trabalho que gera conflito nas relações sócio-profissionais em consequência de: individualismo, isolamento, falta de espaço para falar sobre as vivências de sofrimento, poucos vínculos de confiança e de cooperação, processos de violência e constrangimentos no trabalho; (c) organização do trabalho que impossibilita o trabalhador de colocar sua subjetividade no espaço de trabalho, principalmente pela falta de autonomia, rigidez nas normas de trabalho e repetição das atividades; (d) organização do trabalho que gera riscos psicossoais por: defasagem entre o prescrito e o real, vulnerabilidade do trabalhador diante do sofrimento, problemas de infraestrutura, medo e insegurança na realização das atividades, desqualificação do trabalhador e informalidade do trabalho;

3. Reconhecimento: ausência de reconhecimento e baixa remuneração.

Os fatores de sofrimento que mais se destacaram estão associados à sobrecarga de trabalho, que tem uma origem social e é imposta pela organização do trabalho, sem levar em conta a vontade ou as condições do trabalhador (Mendes, 2007b). O trabalhador sofre na medida em que é impedido de colocar seu ritmo, sua subjetividade e sua inteligência prática nas atividades laborais, tonando-se mais submisso e menos sujeito atuante no contexto de trabalho.

O eixo estratégias defensivas foi descrito nos resultados dos estudos como as reações individuais e/ou coletivas mediante o sofrimento. Estas reações foram caracterizadas pelos seguintes comportamentos: choro, riso, negação, atitudes agressivas, prática de leitura, prática religiosa, atividades físicas, realização de terapias, racionalização, adoção de brincadeiras, negação do sofrimento, projeção, identificação, passividade, improvisação, somatização, visão do trabalho como meio de sobrevivência e afastamento dos fatores causadores de sofrimento. 
A mobilização subjetiva foi descrita nos estudos pelos aspectos que geram engajamento e fortalecimento do vínculo dos profissionais ao trabalho, sendo estes aspectos atrelados à: coesão e integração das equipes de trabalho, criatividade, fazer o que gosta e sentir que o trabalho contribui para a melhoria da sociedade e das pessoas, ressignificação dos problemas socioprofissionais, dinâmica de reconhecimento entre os colegas de trabalho, verbalização do sofrimento, identidade profissional, sentimento de que o trabalho possui relação com os valores pessoais, reconhecimento social gerado pelo trabalho e criação de redes de solidariedade. Enquanto alguns resultados apontaram que as estratégias defensivas utilizadas pelos trabalhadores não têm sido suficientes para protegê-los do adoecimento físico e mental, outros mostraram que os próprios trabalhadores conseguem se organizar de modo protetivo nos ambientes insalubres ou com riscos psicossociais, através da mobilização subjetiva que atua contribuindo na detecção prévia de riscos ou da criação de estratégias coletivas para minimizar o impacto dos riscos.

Os resultados apontaram que o adoecimento mental aparece como consequência do sofrimento vivenciado pelos trabalhadores, ressaltando a importância de transformações nos modelos de gestão, condições e relações de trabalho como mecanismos preventivos. As manifestações associadas ao adoecimento foram identificadas como sintomas psicossomáticos: ansiedade, desgaste físico e emocional, além de cansaço, fadiga, tensão, angústia, impotência, indignação, ambivalência, picos hipertensivos, gastrite, insônia, sonolência, enxaqueca e tendinite. Também foi mencionada a Síndrome de Burnout como uma forma de adoecimento, associada à sobrecarga de trabalho. De acordo com Dejours (2000), esta patologia está atrelada ao excesso de trabalho e à grande necessidade de agradar o cliente em todos os momentos, sem espaço para que o trabalhador possa expressar sua subjetividade e seu descontentamento diante desta dinâmica.

O eixo intervenção foi composto pelos resultados da:

1. Pesquisa-intervenção propriamente dita $\mathrm{e}$ também pelas
2. Alternativas de intervenções recomendadas pelos autores dos estudos. No que diz respeito aos resultados da pesquisa-intervenção, foram destacadas as seguintes mudanças: estabelecimento de confiança entre os trabalhadores, criação de espaços de expressão, reflexão e busca por soluções. Quanto às alternativas de intervenções, os estudos apresentaram a necessidade de incrementar os espaços institucionais de reflexão e discussão sobre o papel do trabalhador, de desenvolver novas maneiras de trabalhar, de promover a saúde no trabalho, de potencializar os espaços de discussão e de convivência rumo à construção coletiva de emancipação profissional, de desenvolver novos sentidos para o trabalho, de melhor equacionar os processos de gestão na organização do trabalho, de efetivar o cumprimento da legislação, de minimizar os riscos à saúde mental e de gerar intervenções que estimulem a participação dos trabalhadores como agentes de mudança das organizações do trabalho.

A análise dos resultados dos estudos mostrou que os eixos temáticos que receberam maior ênfase foram os fatores de prazer e os fatores de sofrimento no trabalho, evidenciando os fatores de sofrimento. As temáticas menos discutidas foram o adoecimento mental e a intervenção. Este dado pode ser explicado pela relação direta dos resultados com os objetivos mais estudados nas pesquisas, os quais estão atrelados à investigação dos fatores de prazer, de sofrimento e da organização do trabalho.

Esta constatação revela que, se, por um lado, os estudos brasileiros que utilizam a psicodinâmica do trabalho como teoria e/ou método estão investigando as principais categorias de análise da abordagem, por outro, estão menos direcionados para a prevenção e intervenção nos aspectos associados ao processo de saúde/doença do trabalhador. Os resultados que apresentaram possibilidades de intervenção, na sua maioria, as descrevem de maneira inespecífica e atrelada a grandes transformações sociais e/ou organizacionais, deixando de citar os efeitos gerados pela própria pesquisa e atuação do pesquisador junto 
aos trabalhadores investigados. Dado preocupante se deparado com um dos objetivos principais da psicodinâmica do trabalho que é, justamente, de intervir buscando a ampliação do espaço público de deliberação e a maior participação dos trabalhadores nas decisões sobre as situações de trabalho, colocando-os em um lugar de agentes de transformação (Heloani \& Lancman, 2004). Sendo assim, se uma importante contribuição da abordagem é a proposta de pesquisa-ação e, através dela, a intervenção, faz-se necessário atribuir maior destaque para estes aspectos nos estudos brasileiros.

$\mathrm{O}$ fato de o adoecimento mental aparecer menos nos resultados pode estar relacionado ao próprio foco da psicodinâmica do trabalho, mais voltado para a análise dos processos atrelados à saúde do que para o adoecimento. De acordo com Merlo (2002), a teoria atribui maior ênfase ao estudo da normalidade do que da patologia, investigando como os trabalhadores conseguem manter o equilíbrio psíquico mesmo estando submetidos aos aspectos geradores de sofrimento nas organizações de trabalho. No mesmo sentido, Dejours (2000) salienta que os trabalhadores fazem uso de estratégias defensivas que anestesiam e mascaram o sofrimento, mas que não são capazes de modificar sua causa. Este processo pode fazer com que as formas de adoecimento não apareçam com tanta ênfase nos resultados dos estudos.

Quanto às lacunas nas investigações que utilizam a psicodinâmica do trabalho no Brasil, podem ser citados: os poucos estudos sobre os fatores positivos relacionados ao trabalho; a necessidade de investigações acerca de temáticas além dos fatores de prazer, sofrimento e organização do trabalho; os poucos estudos acerca de categorias profissionais relacionadas ao trabalho rural; a necessidade de maior ênfase às possibilidades de intervenção e de promoção da saúde mental do trabalhador.

\section{Considerações Finais}

Este estudo teve o objetivo de realizar uma revisão sistemática dos artigos, teses e dissertações nacionais que utilizaram a teoria e /ou o método da psicodinâmica do trabalho nos últimos anos (janeiro de 2007 a dezembro 2013). Os resultados encontrados apontaram que os estudos, em sua grande maioria, estão pautados em métodos qualitativos, fazem uso de diferentes instrumentos de coleta de dados, investigando vivências de prazer e de sofrimento dos trabalhadores, e que a categoria profissional mais estudada é a dos trabalhadores da área da saúde. A análise dos principais resultados dos estudos revelou que as pesquisas brasileiras que utilizam a psicodinâmica do trabalho possuem uma forte característica descritiva, apontando para uma carência em estudos com foco na intervenção e na discussão de ações de promoção da saúde do trabalhador. Entretanto, esta pesquisa possui limitações, pois se utilizou nas buscas apenas o descritor psicodinâmica do trabalho. Assim, este aspecto deve ser considerado na interpretação dos resultados apresentados.

Como indicações para futuros estudos poderiam ser ampliadas as buscas incluindo outros descritores. Também poderiam ser realizadas comparações entre as tendências dos estudos nacionais e os estudos internacionais que utilizam a abordagem da psicodinâmica do trabalho.

\section{Referências}

Bordão-Alves, D. P., \& Melo-Silva, L. L. (2008). Maturidade ou imaturidade na escolha da carreira: Uma abordagem psicodinâmica. Avaliação Psicológica, 7(1), 23-34. Recuperado em http:// www.redalyc.org./pdf/3350/335027183005.pdf

Bruch, V. L. A., \& Monteiro, J. K. (2011). Relações entre colegas como manifestações de resistência ao adoecimento no trabalho. In M. C. Ferreira, J. N. C. de. Araújo, C. P. de. Almeida, \& A. M. Mendes (Eds.), Dominação e resistência no contexto trabalho-saúde (pp. 121-140). São Paulo, SP: Universidade Presbiteriana Mackenzie.

Dejours, C. (1992). A loucura do trabalho: Estudo de psicopatologia do trabalho. São Paulo, SP: Cortez.

Dejours, C. (2000). Entrevista com Dejours. Revista Latinoamericana de Psicopatologia Fundamental, 3(4), 158-163. Recuperado em http://www. redalyc.org/pdf/2330/233018185015.pdf 
Dejours, C. (2004). Da psicopatologia à psicodinâmica do trabalho. Rio de Janeiro, RJ: Editora da Fundação Oswaldo Cruz.

Dejours, C. (2005). O fator humano. Rio de Janeiro, RJ: Editora da Fundação Getulio Vargas.

Dejours, C., Abdoucheli, E., \& Jayet, C. (1994). Psicodinâmica do trabalho: Contribuições da escola dejouriana à análise da relação prazer, sofrimento e trabalho. São Paulo, SP: Atlas.

Heloani, R., \& Lancman, S. (2004). Psicodinâmica do trabalho: O método clínico de intervenção e investigação. Produção, 14(3), 77-86. doi:10.1590/S0103-65132004000300009

Mendes, A. M. (2004). Cultura organizacional e prazer e sofrimento no trabalho: Uma abordagem psicodinâmica. In A. Tamayo (Ed.), Cultura e saúde nas organizações (pp. 48-67). Porto Alegre, RS: Artmed.

Mendes, A. M. (2007a). Da psicodinâmica à psicopatologia do trabalho. In A. M. Mendes (Ed.), Psicodinâmica do trabalho: Teoria, método e pesquisas (pp. 23-48). São Paulo, SP: Casa do Psicólogo.

Mendes, A. M. (2007b). Novas formas de organização do trabalho, ação dos trabalhadores e patologias sociais. In A. M. Mendes (Ed.), Psicodinâmica do trabalho: Teoria, método e pesquisas (pp. 49-87). São Paulo, SP: Casa do Psicólogo.

Mendes, A. M., \& Facas, E. P. (2011). Subjetividade e trabalho com automação. In R. D. de. Moraes \& A. C. L. Vasconcelos (Eds.), Subjetividade e trabalho com automação: Estudo piloto no polo industrial de Manaus (pp. 18-37). Manaus, AM: Editora da Universidade Federal do Amazonas.
Merlo, A. R. C. (2002). Psicodinâmica do trabalho. In M. da. G. Jaques \& W. Codo (Eds.), Saúde mental e trabalho: Leituras (pp. 42-130). Petrópolis, RJ: Vozes.

Merlo, A. R. C., \& Mendes, A. M. B. (2009). Perspectivas do uso da psicodinâmica do trabalho no Brasil: Teoria, pesquisa e ação. Cadernos de Psicologia Social do Trabalho, 12(2), 141-156. doi:10.11606/issn.1981-0490.v12i2p141-156

Schlindwein, V. L. D. C. (2010). Dor e sofrimento oculto: A desproteção social dos trabalhadores do fumo. Barbarói, 32(1), 82-97. Recuperado em http://bvsalud.org/portal/resource/pt/lil571121

Silva, A. R. (2007). O significado do trabalho na terra do fumo: Perspectivas dos agricultores frente ao sistema integrado de produção industrial em Santa Cruz do Sul/ RS (Dissertação de mestrado não publicada, Universidade de Santa Cruz do Sul, RS, Brasil).
Recebido: 09/06/2014

$1^{a}$ revisão: 05/10/2014 Aceite final: 08/10/2014 